\title{
Optimization of PWM for Overmodulation Region of Two-level Inverters
}

\author{
Péter Stumpf*, Sándor Halász ${ }^{\dagger}$ \\ *Budapest University of Technology and Economics, Dept. of Automation and Applied Informatics \\ $\dagger$ Budapest University of Technology and Economics, Dept. of Electric Power Engineering \\ Budapest, Hungary, e-mail: stumpf@aut.bme.hu,halasz.sandor@vet.bme.hu
}

\begin{abstract}
Three optimized PWM techniques for the overmodulation region of two-level inverter-fed ac drives are introduced and investigated from harmonic loss minimization point of view. The optimization is elaborated for the lowest loss-factor, which is proportional to the square of rms value of current harmonics. The loss-factors are computed for different switching numbers as the function of the motor fundamental voltage. It is shown that, respect to the motor heating and torque ripples, the acceptable drive condition can be guaranteed by relatively low value of inverter switching frequency up to $96-97 \%$ of maximal possible motor voltage. Furthermore, it is shown that, the so-called Three vector methods have considerably better performance in the lower part of the overmodulation region than the so-called Two vector method for the same number of switching. The performance of the techniques is compared with other existing PWM techniques. The paper discusses the implementation details of the proposed optimal PWM techniques. The theoretical results are verified by experimental and simulation tests.
\end{abstract}

Index Terms-Pulse width modulated inverters, Optimization methods, Induction machines, Losses, Overmodulation

\section{INTRODUCTION}

Pulse Width Modulated (PWM) three phase two-level voltage source inverter (VSI) is one of the most common power converter topologies in ac motor drive applications. In the last decades investigation of PWM techniques has been a hotspot in controlling of VSI as they are directly related to the efficiency of the overall system.

The peak of the maximum output phase voltage of a three phase two-level VSI in the so-called six-step or square-wave mode of operation is limited to $U_{1 \max }=4 U_{D C} / \pi$, where $2 U_{D C}$ is the DC-link voltage of the inverter. By operating the widely applied standard PWM techniques, like Space Vector Modulation (SVM) or Discontinuous PWM (DPWM) methods, in the so-called linear region, only $90.7 \%$ of $U_{1 \max }$ can be reached. Therefore, to improve the DC-link utilization and to expand the output voltage to $U_{1 \max }$ the VSI should be operated in the overmodulation region.

Assuming that, the VSI is supplied by a diode bridge rectifier operating in continuous conduction mode the DClink voltage in ideal case can be expressed as $2 U_{D C}=$ $3 \hat{U}_{L L} / \pi$, where $\hat{U}_{L L}$ is the amplitude of the input lineto-line voltage. Hence, the maximum voltage output phase voltage at the border of linear modulation is $U_{1}=0.907$. $6 \sqrt{3} / \pi^{2}\left(\hat{U}_{L L} / \sqrt{3}\right)=0.955\left(\hat{U}_{L L} / \sqrt{3}\right)$. So mass-produced standard induction machines rated at the input line voltage and frequency would not reach rated operating point in the linear region. It means that, by taking into consideration the voltage drop in the rectifier as well, more than $5 \%$ of the power is inaccessible from a motor fed by a VSI operated only in the linear region [1]. Consecutively, the rated operational point and the flux weakening area of a mass-produced standard induction machines rated at the input line voltage are in the overmodulation region. Thus, the quality of the drive in this region is of great importance.

Recently increasing attention has been paid to high speed induction and synchronous machine drives to reduce system size and improve power conversion efficiency [2]. It poses challenges not only in the field of electric motor design but also in the field of industrial electronics. The basic features of three-phase PWM controlled VSI fed high speed drive are the necessarily high fundamental (synchronous) frequency $f_{1}$ (from a few hundred up to thousands) and the limited carrier (switching) frequency $f_{c}(\leq 15-25 \mathrm{kHz})$. So a high speed drive system does not only operate at the rated operational point and the flux weakening area in the overmodulation region but the $m_{f}=f_{c} / f_{1}$ frequency ratio is also a low number (usually $m_{f}<21$ ).

It should be noted that, the problems encountered previously with the high speed drives also appear in high-pole count motors, used widely for hybrid and electric vehicles. As in this case the number of poles is high, the required synchronous frequency $f_{1}$ can be higher than $1 \mathrm{kHz}$, while the output speed is a few thousand rpm. Furthermore, in very high power drive systems, the thermal constraints of semiconductor devices also restrict the switching frequency to a few hundred $\mathrm{Hz}$ resulting also a very low frequency ratio even at standard $f_{1}$ fundamental frequencies.

The aim of this paper is to propose and demonstrate harmonic loss optimized PWM control techniques in overmodulation region for low frequency ratios, which makes them applicable to operate high speed, high pole-count drives or high power drive systems in the overmodulation region of good quality.

\section{STATE OF THE ART}

\section{A. Overmodulation}

In the linear region of feed-forward (carrier based) space vector based PWM techniques, like SVM, the reference voltage vector has a uniform magnitude and rotates at a constant angular frequency. In the overmodulation region the angle and the magnitude of the reference voltage vector should be modified by passing it through a preprocessor or premodulator [3], [4], [5], [6]. It results in a non-uniform magnitude or nonuniform angular frequency (or both) of the reference voltage vector. 
In the literature two approaches are followed for overmodulation of space vector based PWM techniques. In the first approach, called 2-zone algorithms, the overmodulation region is divided into two zones [3], [6], [7]. The algorithms, called 1-zone algorithms, following the second approach treat the overmodulation range as a single undivided region from the computational point of view [8], [9].

In the case of standard 2-zone algorithm, introduced in [3], in the first part of the overmodulation region $(0.907 \leq$ $m \leq 0.9514$ ) only the magnitude of reference voltage is modified. In the second part of the overmodulation region $(0.9514 \leq m \leq 1)$ both the magnitude and the angle of the reference voltage vector are modified by the premodulator. A modified 2-zone algorithm is presented in [6], [10]. The modified technique has a considerably better harmonic performance than the standard one in the upper part of the overmodulation region as demonstrated in [6]. As different control variables and calculation procedures are used in the two regions, 2-zone algorithms require significant computational effort [9].

In the case of the 1-zone algorithm, introduced in [8], the reference voltage vector has a constant magnitude, but its angle is varied based on simple equations. The advantage of this technique is its simple implementation, however, the low-order harmonic distortion in line currents is much higher than in case of the standard 2-zone algorithm. An improved 1-zone algorithm is introduced in [9], where the magnitude of the voltage vector is also varied by simple equations. It significantly reduces the computational effort comparing to the standard 2-zone algorithm or the standard 1-zone method introduced in [8]. Furthermore, the algorithm reduces the total harmonic distortion in the line current significantly compared to standard 1-zone method. However, the harmonic distortion is still marginally higher than that in case of the standard 2zone algorithm.

Paper [11] introduces a predictive overmodulation technique in medium-voltage inverters operating at low switching frequencies. A general SVM procedure for overmodulation is described for $n$-phase drives, where $n$ is an odd number, in [12]. Overmodulation region of inverters is thoroughly studied in closed loop applications [13], [14]. A novel harmonic estimator, which eliminates the unavoidable low order harmonics causing problems in vector controlled drives is described in [13]. Paper [14] presents an overmodulation scheme for sinusoidal PWM used in Field Oriented Controlled (FOC) traction drives, when the switching frequency is only a few hundred Hertz. Overmodulation region of PWM techniques has key importance not only in motor drives but also in grid connected inverters. An overmodulation strategy has been proposed, tested and verified for a $250 \mathrm{~kW}$ grid-connected photovoltaic inverter in [15].

In the current paper, similar to [3], the overmodulation region is divided into two regions. They are called as "Low voltage region" and "high voltage region" (to be discussed later). From the implementatio point of view, the presented PWM techniques are 1-zone algorithms, as the same calculation procedure can be used for the whole overmodulation region.

\section{B. Optimal PWM}

Instead of applying carrier based techniques, programmed modulation strategies can be used as well to control VSIs. In this case the overall approach to define the switching times is based on the minimization of a suitable objective function which typically represents system losses [1]. Applying optimal PWM techniques for ac drive systems has been investigated since the seventies of the last century [16], [17], [18], [19], [20], [21], [22], [23], [24]. An overview of optimal modulation techniques is given in [20]. A space vector based analysis for determining optimal switching angles with reduced computational effort for drives with very low switching frequency for the whole modulation range is introduced in [22]. In [22] the weighted Total Harmonic Distortion (THD) of voltage is considered for minimization. Paper [23] introduces two algorithms, a frequency domain and a synchronous reference frame based one, to minimize the low-order harmonic torques in induction motor drives, operated at a low frequency ratio. Paper [25] presents a synchronous optimal PWM method with practical implementation issues for modular multilevel converters. A comparison between time and frequency domain based optimization of PWM techniques is given in [24].

In the current paper the optimization is elaborated for the lowest loss-factor, which is proportional to the square of rms value of current harmonics. In the literature the optimization is mostly done for very small pulse ratios, like 5,7 and 9 . In the current paper the optimization is done for higher, but still low pulse ratios (like $13,15,21,31,43$ ) as well, to obtain a better harmonic performance and drive condition with good quality.

Nowadays, thanks to the high perfomance digital devices, the implementation of optimal methods is considerably simpler allowing their wider spread in practice. The paper [26] demonstrates the use of a digital card flashmemory to follow a preprogrammed optimal PWM pattern. The current paper also discusses the implementation details of the proposed optimal PWM techniques.

\section{Loss-factor}

The harmonic losses of the machine in the overmodulation region are generally characterized by the loss-factor [27], which can be calculated as follows

$$
K_{\Psi}^{\prime}=\left(\sigma L_{s}\right)^{2} \sum_{\nu>1}^{\infty} i_{s, \nu}^{2}=\Psi_{s}^{2}-1=\sum_{\nu>1}^{\infty} \frac{U_{s, \nu}^{2}}{U_{s, 1}^{2} \nu^{2}}
$$

where $i_{s, \nu}$ and $U_{s, \nu}$ are the stator current and voltage harmonics of the order $\nu$, respectively. $\sigma L_{s}$ is the stator transient inductance, where $\sigma=1-\frac{L_{m}^{2}}{L_{s} L_{r}}$, where $L_{s}, L_{r}$ and $L_{m}$ are the stator, rotor and the mutual inductance, respectively. $\Psi_{s}$ is the rms value of the stator flux. In (1) all the values are in pu system and it was assumed that the machine operates at its rated stator flux. In opposite case (1) should be multipled by $\Psi_{s}^{2} / \Psi_{\text {rated }}^{2}$. The base values of the pu system are the rated phase current and voltage, for the flux the ratio $U_{s, \text { rated }} / \omega_{1 \text { rated }}$ (where $\omega_{1 \text { rated }}$ is the rated electric synchronous angular velocity) and for the impedance $U_{\text {rated }} / I_{\text {rated }}$. Later on, we will use the relative loss-factor $K_{\Psi}=K_{\Psi}^{\prime} / 0.00215$, where $K_{\Psi}^{\prime}=0.00215$ is the loss-factor 

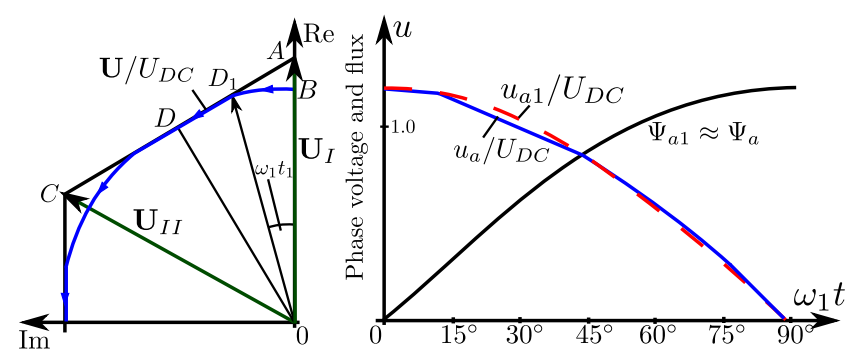

(a) mode 1

Fig. 1. Voltage vector path and phase voltage and flux versus time

of the inverter operating in six-step mode [17]. In practice it is desirable to obtain a $K_{\Psi}$ loss-factor value lower than 0.1 as usually in this case no underrating or additional cooling of the motor is necessary.

\section{Optimum solution}

The optimum solution means the determination of lossfactor in case of infinitively high switching frequency of the VSI. In overmodulation region, for the fundamental voltage $m=U_{1} / U_{\max }>0.907$ the optimized increase of the voltage can be performed according to [17], [18]. According to the modulation index $m=U_{1} / U_{1 \max }$, two operational modes are possible. In the first mode (Fig.1(a)) the motor voltage vector $\mathbf{U}$ moves along the circle $B D_{1}$ with fundamental angular velocity $\omega_{1}$ until it reaches at the $t_{1}$ time the point $D_{1}$ of $A C$ line. Then the voltage vector moves along the line $D_{1} D$ with the same angular velocity $\omega_{1}$ and at the moment $\pi /\left(6 \omega_{1}\right)$ the vector will be in $D$ point. The maximum modulation index of the first operational mode, which takes place when $D_{1}$ point coincidences with $A$ point, can be expressed as $m=-\sqrt{3} \ln (\tan (\pi / 6))=0.9514$ [17], [18]. It should be noted that the first operational mode is the same as "Overmodulation Mode I" in [3].

In the second operational mode of the investigated $\pi / 6$ duration the $\mathbf{U}=\pi U_{1 \max } / 3$ constant voltage vector stays in the point $A$ for the time $t_{2}$ (Fig.1(b)). At $t_{2}$ the voltage vector turns by angle $\omega_{1} t_{2}$ in $D_{1}$ point and moves along $D_{1} D$ line with the constant angular velocity $\omega_{1}$. From Fig.1(b) it can be seen that the difference between the phase voltage or flux and their fundamental components becomes sensible. Therefore, the voltage harmonics and current harmonic losses of this operational mode reach significant values. The angles $\omega_{1} t_{1}$ and $\omega_{1} t_{2}$ as the function of the modulation index $m=U_{1} / U_{1 \max }$ can be seen on Fig.2(a).

The second operational mode is similar to "Overmodulation Mode II" in [3].

The loss-factor is drawn in Fig.2(b). This loss-factor curve is computed as $\Psi^{2}-1$ by numerical integration of $\boldsymbol{\Psi}$ flux vector [17]. In the first operational mode the loss-factor is very low. Therefore, it is impossible to distinguish the phase flux from its fundamental component as it can be seen on Fig.1(a) (the flux is given in voltage scale). The maximal $K_{\Psi}=0.024$ value of this mode belongs to $m=U_{1} / U_{1 \max }=0.9514$.

The first eight harmonic voltage components (with correct sign of vector presentation) are presented in Fig.3. Only harmonics of order $\nu=1 \pm 6 K$ are possible $(K=0,1,2,3 \ldots)$. From Fig. 3 it can be seen that, in the first operational mode the voltage harmonics for the same $K$ have the same amplitude.

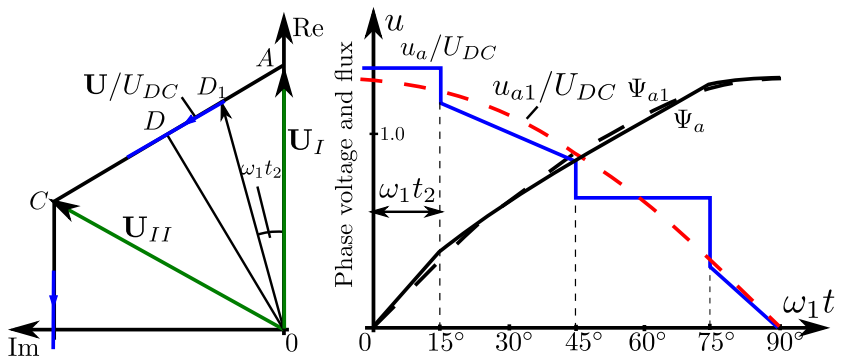

(b) mode $2, \omega_{1} t_{2}=\pi / 12$

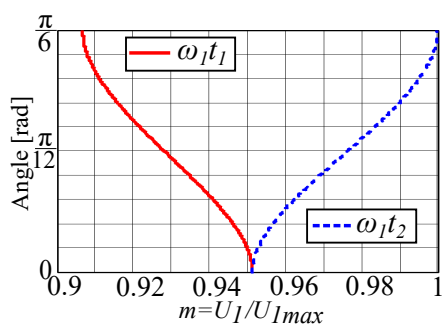

(a) $\omega_{1} t_{1}$ and $\omega_{1} t_{2}$

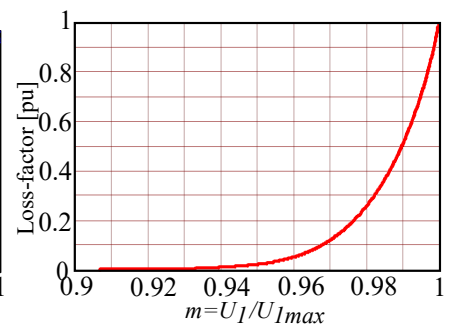

(b) $K_{\Psi}$ loss-factor
Fig. 2. $\omega_{1} t_{1}$ and $\omega_{1} t_{2}$ angles and $K_{\Psi}$ loss-factor as the function of $m=$ $U_{1} / U_{1 \max }$

The motor harmonic losses as well as the torque pulsation are mainly determined by harmonic currents of order -5 and 7 . These losses decrease sharply with the decrease of the motor voltage. However, the motor torque pulsation really decreases only in the first operational mode. This is clear from Fig.3 since the torque of order 6 is determined by the sum of the torques from currents of order -5 and 7 . These torque components have different sign for different sign of voltage harmonics in the second part of the second operational mode $(m>0.97)$. It results in practically constant $6^{\text {th }}$ order torque component in this region, while the ampltiude of the voltage harmonics changes.

It should be noted that, the conclusions presented previously, assuming infinitively high switching frequency, are valid for multi-level inverters too. Thus, it is impossible to obtain better results than presented above (Fig.2(b)).

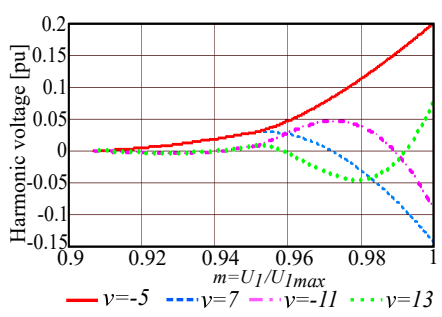

(a) $\nu=5,7,11,13$

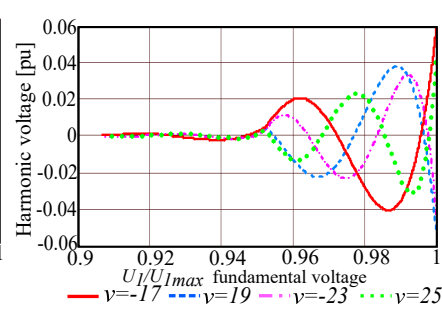

(b) $\nu=17,19,23,25$
Fig. 3. Harmonic voltages for infinitively high switching frequency $(\gamma=\infty)$

\section{E. Waveform Quality}

In the current paper the optimization is elaborated for the lowest loss-factor, which is proportional to the square of rms value of current harmonics (see (1)).

In most cases the optimization is done to minimize the THD 
in line current [1], where $I_{T H D}$ is defined as

$$
I_{T H D}=\sqrt{\frac{\sum_{\nu>1}^{\infty} i_{s, \nu}^{2}}{i_{s, 1}^{2}}}
$$

where $i_{s, 1}$ is the fundamental current component. It should be noted, $I_{T H D}$ depends on machine parameters. Therefore, in the literature another quantity, the weighted THD of the voltage $V_{W T H D}$ is also applied as a performance index of PWM strategies as it is independent of the motor parameters [1], [6], [5], [22], [28]

$V_{W T H D}$ is defined as

$$
V_{W T H D}=\sqrt{\frac{\sum_{\nu>1}^{\infty} U_{s, \nu}^{2} / \nu^{2}}{U_{s, 1}^{2}}}=\sqrt{K_{\Psi}^{\prime}}
$$

As it can be seen the $V_{W T H D}$ is the square root of the loss-factor. For the proper comparison with other techniques, not only the loss-factor, but the $I_{T H D}$ and $V_{W T H D}$ will also be presented for all investigated optimized PWM techniques.

\section{OPTIMIZATION OF PWM FOR OVERMODULATION REGION}

The computation problem was investigated also in [1], [16], [17], [18], [22], [28]. For a given number of inverter switching and a desired $V$ fundamental voltage the Lagrange function

$$
F=\frac{\Psi^{2}}{\Psi_{1}^{2}}-1+\lambda\left(U_{1}^{2}-V^{2}\right)
$$

must be minimized, where $F$ depends on $\theta_{i}$ switching (commutation) angles and on $\lambda$. The computation uses NewtonRaphson method. The computation starts from a given value of $V$ and a selected voltage vector sequence as well as initial switching angles. It continues until all the first derivatives of $F$ become close to zero. Due to the symmetry of vector paths computations were performed only for $0 \leq \omega_{1} t \leq \pi / 6$ sector (Fig.1), where only $\mathbf{U}_{I}=\frac{4}{3} U_{D C}$ and $\mathbf{U}_{I I}=\mathbf{U}_{I} e^{j \pi / 3}$ and zero voltage vectors 0 and 7 can be used.

The number of switching on $1 / 6^{\text {th }}$ of the fundamental period is denoted by $\gamma$. For a given $\gamma$ the number of applying voltage vectors is $(\gamma+1) / 2$, the number of varying switching angles is $(\gamma-1) / 2$. The total number of angle parameters with $\theta_{1}=0, \theta_{(\gamma+3) / 2}=\pi / 6$ and $\lambda$ is $(\gamma+3) / 2+1$.

It should be noted the number of switching over one fundamental period is $6 \times \gamma$. For the widely applied SVM the number of switching over one fundamental period is $6 m_{f}$. It means that $\gamma$ has similar meaning as $m_{f}$, so it gives the ratio between the switching frequency and the fundamental frequency.

The computations were performed for different number of switching on $1 / 6^{\text {th }}$ of the fundamental period: $\gamma=$ $5,7,9,11,13,15,21,31,43$.

For demonstration the situation for $\gamma=7$ is presented in Fig.4 where the voltage vector sequence in Fig.4(a) is $\mathbf{U}=\left[\mathbf{U}_{I}, \mathbf{U}_{I I}, \mathbf{U}_{I}, \mathbf{U}_{I I}\right]$ while in Fig.4(b) it is $\mathbf{U}=$ $\left[\mathbf{U}_{I}, 0, \mathbf{U}_{I}, \mathbf{U}_{I I}\right]$. The stator phase flux, its fundamental component and the applied voltage vector sequence are presented for $U_{1}=0.95 U_{1 \max }$ (Fig.4(a)) and for $U_{1}=0.92 U_{1 \max }$ (Fig.4(b)). Later on, the first case, when zero voltage vector is not applied, is called the Two vector method, and the case,

when zero voltage vector is also applied is called the Three vector method.
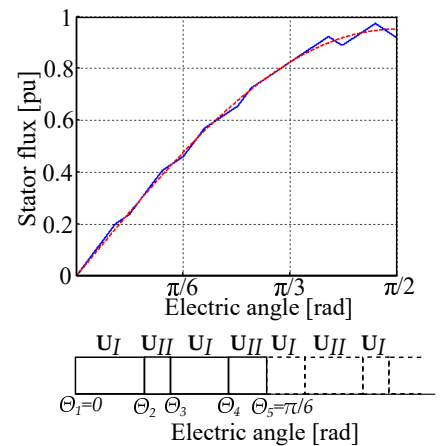

(a) $U_{1}=0.95 U_{1 \max }$, two vector method

Fig. 4. Stator phase flux (blue line), its fundamental component (dashed line) and the applied voltage vector sequence, $\gamma=7$

\section{A. Two vector method - "High voltage region"}

This region correspondences to the operation mode 2 in 1(b). The voltage vector path never moves along a fundamental voltage vector path. Therefore, only the two active voltage vectors can be used to obtain a loss-optimal PWM control. Thus, the zero voltage vectors are not used in this case. This method is introduced in [18]. The same vector sequence is also studied for optimized PWM in [22] for $\gamma=5,7,9$ and 11, where the optimization is done in order to minimize $V_{W T H D}$. Later on, the two vector method is abbreviated as $2 \mathrm{~V}$.

The calculated optimal switching angles for $\gamma=13$ are presented in Fig.5(a).

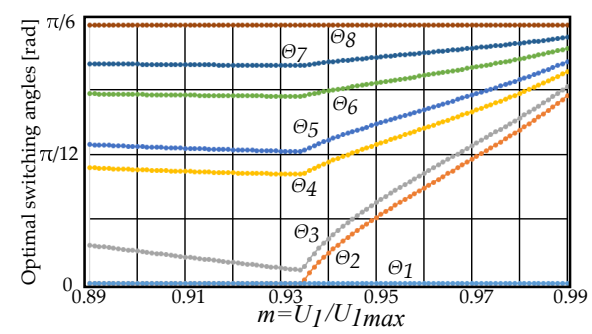

(a) Two vector method $(2 \mathrm{~V})$

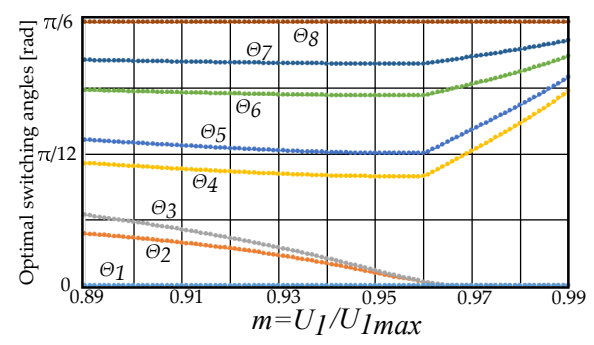

(b) Three vector method, type $1,(3 V-T 1)$

Fig. 5. Optimized switching angles, $\gamma=13$

The loss-factors for $\gamma=5,7,9,11,13,15,21,31$ and $\gamma=$ 43 are given in Fig.6. In practice it is desirable to obtain a $K_{\Psi}$ loss-factor value lower than 0.1 , because the underrating of the motor is usually not necessary in this case. According to Fig.6 the loss-factor is lower than 0.1 only in a narrow region of the motor voltage using two vector method. The performance 
can be improved by increasing $\gamma$, however even for $\gamma=43$ it is not possible to obtain loss-factor under 0.1 for the whole overmodulation range.

In Fig.7(a) the voltage harmonics of order $\nu=-5,7,-11$ and 13 are drawn for $\gamma=13$. In this case, when $m \leq 0.934$ the first switching angle $\theta_{2}=0$, but $\gamma$ stays 13 since at $\omega_{1} t=0$ there are two switchings (one-one in phases b and c). Figure 7(d) presents the voltage harmonics for $\gamma=31$.

Based on Fig.7(a), Fig.7(d) and Fig.3 it can be concluded that, in the $m \geq 0.95$ region the voltage harmonics have practically the same values for $\gamma=13$ (Fig.7(a)), $\gamma=31$ (Fig.7(d)) and for infinitively high switching frequency $(\gamma=\infty$, Fig.3). Thus, it is worth to optimizing the PWM only in the low voltage region. Furthermore, as the increase of the switching frequency does not change the amplitude of the low order torque harmonics in the $m=\geq 0.95$ region, it is impossible to decrease the torque pulsation in sensible rate in this region.

\section{B. Three vector method - "Low voltage region"}

This region correspondences to the operation mode 1 in 1(a). The voltage vector path from $t=0$ is moving along $\mathbf{U}_{1}$ vector path, therefore the zero voltage vectors should be used as well. As it will be shown later, by using the zero voltage vectors, the loss-factor values, at least in important part of the voltage region, can be sensibly decreased.

The zero voltage vectors should be applied in the initial part of the voltage vector sequence. In the paper two possible voltage vector sequences are studied: $\mathbf{U}=$ $\left[\mathbf{U}_{I}, 0, \mathbf{U}_{I}, \mathbf{U}_{I I}, \mathbf{U}_{I}, \mathbf{U}_{I I}, \ldots\right]$ and $\mathbf{U}=\left[0, \mathbf{U}_{I}, \mathbf{U}_{I I}, \mathbf{U}_{I}, \ldots\right]$. Later on the first one is referred to as type 1 (abbreviated as $3 \mathrm{~V}-\mathrm{Tl}$ ) and the second one as type 2 (abbreviated as $3 \mathrm{~V}-\mathrm{T2}$ ).

As it was mentioned before, due to the symmetry of vector paths, computations were performed only for $0 \leq \omega_{1} t \leq \pi / 6$ sector. It should be noted in the second half of sector $1(\pi / 6 \leq$ $\left.\omega_{1} t \leq \pi / 3\right)$ the last elements of the voltage vector sequence for $3 V-T 1$ and $3 V-T 2$ are $\mathbf{U}=\left[\ldots, \mathbf{U}_{I}, \mathbf{U}_{I I}, 7, \mathbf{U}_{I I}\right]$ and $\mathbf{U}=$ $\left[\ldots, \mathbf{U}_{I}, \mathbf{U}_{I I}, 7\right]$, respectively.

Both $3 V-T 1$ and $3 V-T 2$ voltage vector sequences are studied for optimized PWM in [22] for $\gamma=5,7,9$ and 11.

The calculated optimal switching angles for $\gamma=13$ using $3 \mathrm{~V}-\mathrm{Tl}$ are presented in Fig.5(b).

Our results of computations for $\gamma=$ $5,7,9,11,13,15,21,31$ and 43 are presented in Fig.6 and 7 , respectively.

It can be seen on Fig. 6 that, in the lower part of the overmodulation region the loss-factor for the three vector methods is much smaller than for the two vector method for the same $\gamma$. Furthermore, the magnitude of low voltage harmonics (see Fig.7(b)),7(c), 7(e)) became very close to the case of $\gamma=\infty$ (Fig.3). By comparing the three vector methods $3 V-T 1$ and $3 V-T 2$, it can be concluded that $3 V-T 2$ has a better performance than $3 V-T 1$ in the whole overmodulation range when $\gamma$ is a small value (see Fig.6(a) when $\gamma=7$ ). By increasing $\gamma$ the performance of $3 \mathrm{~V}-\mathrm{Tl}$ becomes better at the beginning of the overmodulation region. By increasing $\gamma$ this region expands. For example $3 \mathrm{~V}-\mathrm{T} 2$ is better than $3 \mathrm{~V}-\mathrm{Tl}$ when $m>0.907$ if $\gamma=11$. When $\gamma$ is increased to 21 the performance of $3 V-T 2$ is better only for $m>0.945$. For larger $\gamma$ values the difference between $3 \mathrm{~V}-\mathrm{Tl}$ and $3 \mathrm{~V}-\mathrm{T} 2$ in the middle of the overmodulation region becomes negligible. Therefore, $3 \mathrm{~V}-\mathrm{T} 1$ has better performance than $3 \mathrm{~V}-\mathrm{T} 2$ in the lower part of overmodulation region $(m \leq 0.9514)$ when $\gamma>21$.

In the upper part of overmodulation region (around $m>$ 0.95) the duration of the zero voltage vector becomes zero consequently the switching number decreases by 4 for $3 \mathrm{~V}$ $T 1$ and by 2 for $3 V-T 2$. The three vector methods effectively reduce to a two vector method with $\gamma *=\gamma-4(3 \mathrm{~V}-\mathrm{Tl})$ or $\gamma *=\gamma-2(3 V-T 2)$. As it can be seen on 6(a), the loss-factor curve of $3 V-T 2$ for $\gamma=15$ and $\gamma=11$ for the upper part of the overmodulation region is the same as in the case of $2 \mathrm{~V}$ when $\gamma=13$ and $\gamma=9$, respectively.

Probably for higher value of $\gamma$ more zero voltage vectors should be used, but according to our calculations for $\gamma \leq 43$ even the use of two zero voltage vectors could not furhter decrease the loss-factor in the overmodulation region.

The voltage vector sequence $\mathbf{U}=\left[0, \mathbf{U}_{I}, \mathbf{U}_{I I}, \mathbf{U}_{I}, \mathbf{U}_{I I}, \ldots\right]$ is applied for VSI in [23], [29] and in [30] as well, but only for the linear range of modulation. In papers [23], [29] the technique is called as advanced bus-clamping pulsewidth modulation (ABCPWM) method. In paper [23] the ABCPWM technique is applied and demonstrated for closed loop control of induction machine. Paper [29] proposes a hybrid PWM technique termed as RTRHPWM which employs ABCPWM in conjunction with a conventional switching sequence to reduce pulsating torque and harmonic distortion of line current in induction motor drives. In paper [30] it is demonstrated that this voltage vector sequence can reduce the maximum value of the flux linkage and the core losses in the circulating current filter of parallel connected VSIs.

\section{TORQUE PULSATIONS}

The motor torque pulsation is computed by neglecting the motor stator and rotor resistances. In this case the harmonic currents are restricted only by the stator transient reactance, therefore the motor torque pulsation is determined with a good approximation as follows:

$$
\Delta m=\left(\boldsymbol{\Psi}_{s, 1}-\mathbf{i}_{s 1}, \sigma L_{s}\right) \times \Delta \mathbf{i}_{s},
$$

where $\boldsymbol{\Psi}_{s, 1}$ and $\mathbf{i}_{s, 1}$ is the stator fundamental flux and stator current, respectively. $\Delta \mathbf{i}_{s}$ is the harmonic current vector. In synchronous rotated coordinate system under no-load condition the first term in (5) aligns along imaginary axis. Therefore,

$$
\Delta m=\left(\Psi_{s, 1}-i_{s, 1} \sigma L_{s}\right) \cdot \Delta R e\left[\mathbf{i}_{s}\right]
$$

The torque time function is drawn in Fig. 8 for $\gamma=13,31$ and $\gamma=\infty$. It can be seen that, the increase of the switching number can not decrease the $6^{\text {th }}$ torque component effectively. At the same time, the use of $3 \mathrm{~V}-\mathrm{Tl}$ leads to an effective decrease of higher order torque components comparing to the $2 \mathrm{~V}$ method in the lower voltage region $(m<0.95)$. The frequencies of these two dominant components are $3(\gamma \pm 1) f_{1}$, where $f_{1}$ is the fundamental frequency.

Comparing $3 V-T 1$ and $3 V-T 2$ it can be concluded, the $6^{\text {th }}$ torque component is considerably lower in the first case.

As it was mentioned previously, three vector methods effectively reduce to a two vector method with $\gamma *=\gamma-4(3 \mathrm{~V}-\mathrm{Tl})$ or $\gamma *=\gamma-2(3 V-T 2)$ in the upper part of the overmodulation 


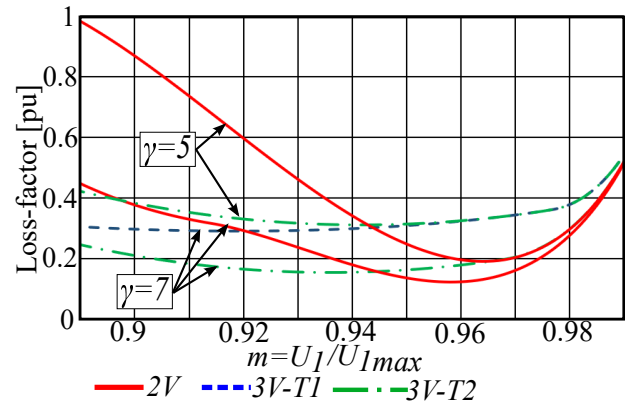

(a) $\gamma=5,7$

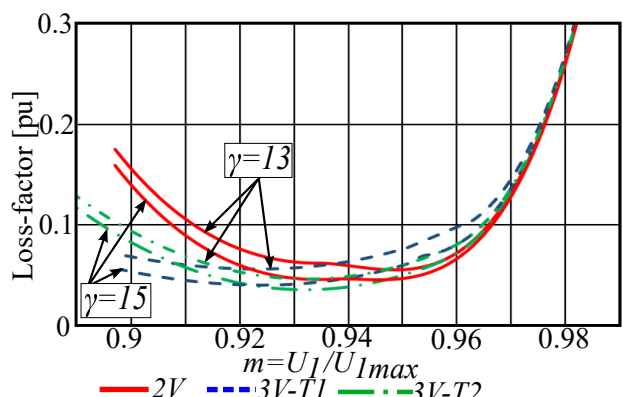

(c) $\gamma=13,15$

Fig. 6. Comparison of $K_{\Psi}$ loss-factor as the function of $m=U_{1} / U_{1 m a}$

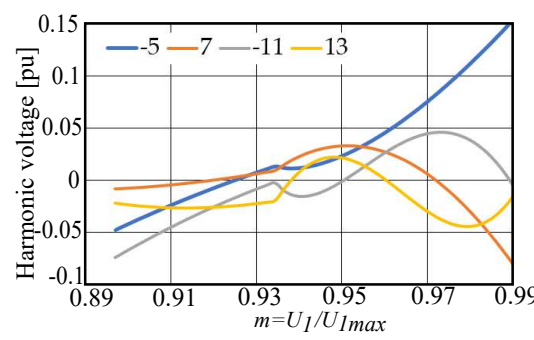

(a) $2 \mathrm{~V}, \gamma=13$

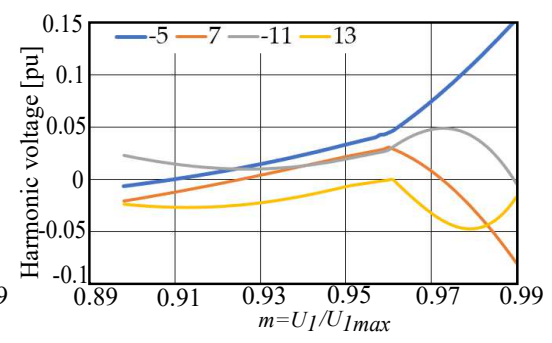

(b) $3 \mathrm{~V}-\mathrm{Tl}, \gamma=13$

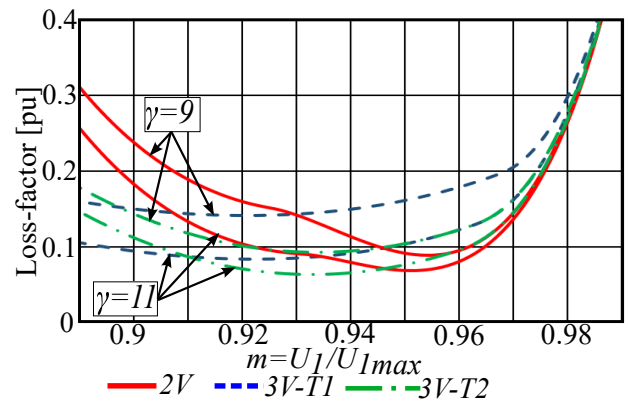

(b) $\gamma=9,11$

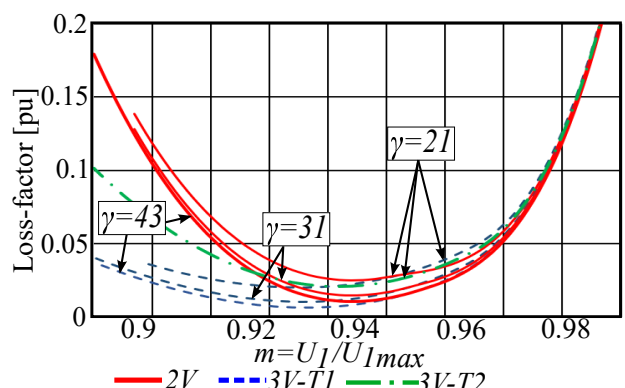

(d) $\gamma=21,31,43$

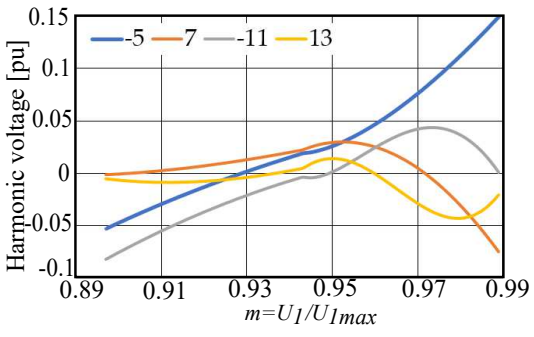

(d) $2 V, \gamma=31$

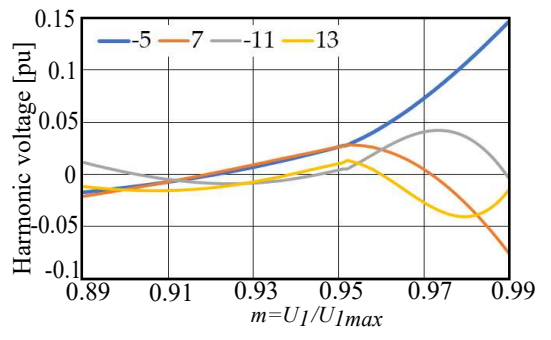

(e) $3 V-T 1, \gamma=31$

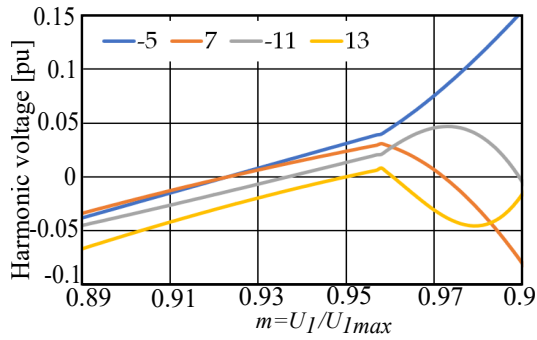

(c) $3 V-T 2 \gamma=13$

Fig. 7. Harmonic voltages as the function of $m=U_{1} / U_{1 \max }$

region. Therefore, $\gamma=9$ on Fig.8(b), $\gamma=11$ on Fig.8(c) and $\gamma=27$ on Fig.8(e), when $m=0.96$ and 0.98 .

\section{Digital Implementation}

The practical aspects of implementing PWM techniques have great importance. The PWM peripheral modules of upto-date, cheap and powerful microcontrollers $(\mu C)$ and Digital Signal Processors (DSP) support a wide variety of operation modes and have many features, which makes them proper for motor control applications. Generally these PWM modules consist of an up-down counter, a Period Register $(P R D)$ and three Compare Registers, one for each phase $\left(C M P_{i}\right.$, $i=a, b, c)$.
There are many different approaches to realize commonly used carrier based techniques like SVM. The implementation of the most commonly used SVM in the linear modulation range is straightforward. Generally an Interrupt Service Routin (ISR) is called at the negative or the positive or both peaks of the triangular signal, which calculates the reference signals for each phase. They are latched into the $C M P_{i}(i=a, b, c)$ of the PWM peripheral to generate the switching signals.

The operation in overmodulation region adds additional complexity, which makes the implementation more difficult. Some application notes written by the vendors of digital devices suggest some methods for the realization of SVM in the overmodulation region.

In the following, the implementation of the optimized 

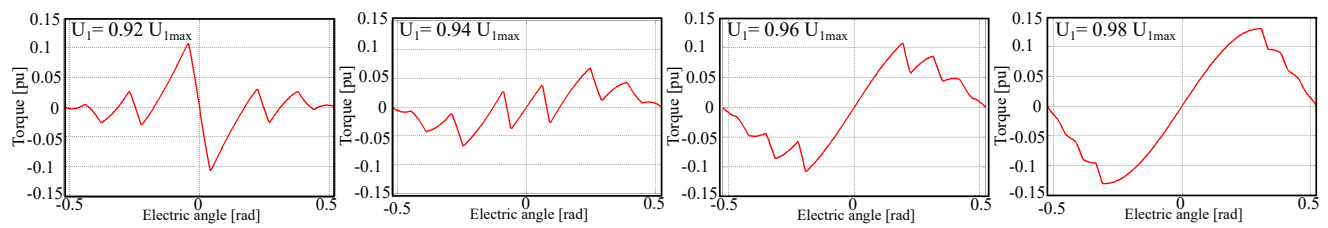

(a) $2 V, \gamma=13$
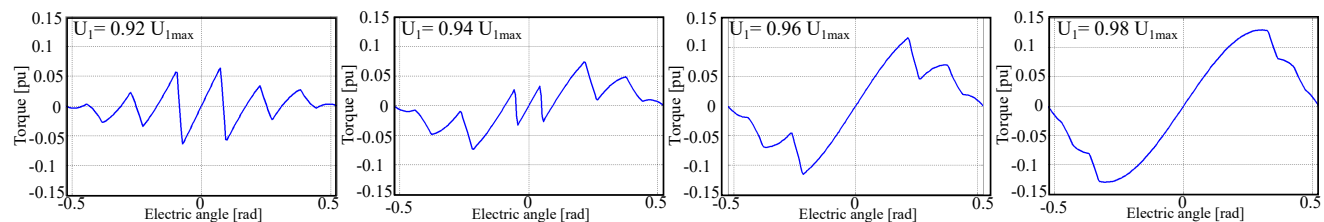

(b) $3 V-T 1, \gamma=13$
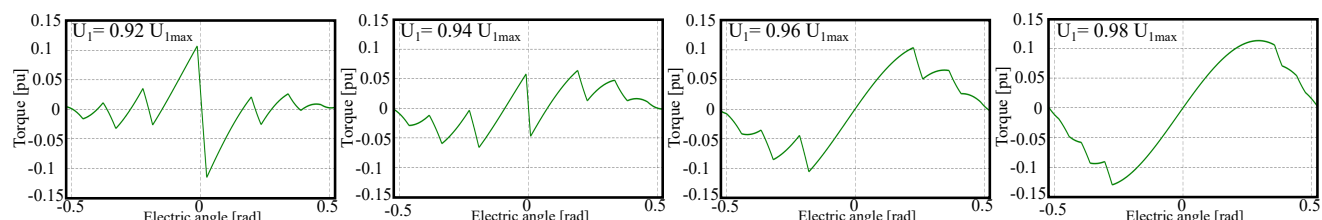

(c) $3 V-T 2, \gamma=13$
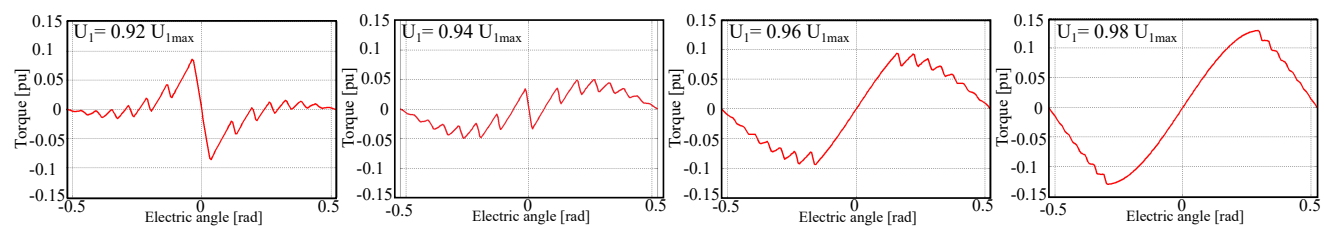

(d) $2 V, \gamma=31$
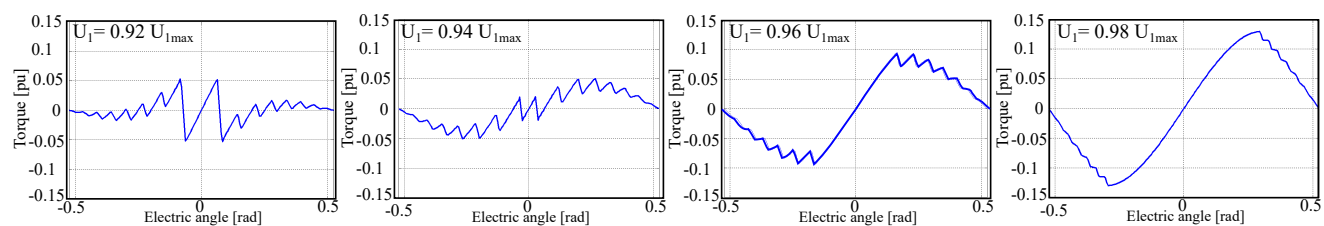

(e) $3 V-T 1, \gamma=31$
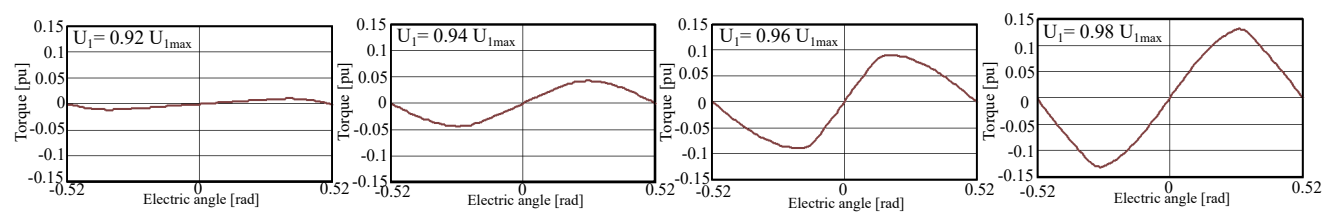

(f) $\gamma=\infty$

Fig. 8. Torque pulsation at no-load

PWM techniques introduced in the paper will be explained. They are succesfully implemented by the authors on a 16-bit $\mu C$ (dsPIC33EP512MU810) and on a 32-bit DSP (TMS320F28379D). A few parameters and features of the two devices are listed in Table I.

The angle values calculated offline should be stored in the flash memory of the digital device as a form of a two dimensional array. Each row of the array contains the angles for a given modulation index $m=U_{1} / U_{\max }$. The number of rows depends on how many evenly spaced points are defined for $m$ between the two endpoints of the overmodulation region $(0.907 \leq m \leq 1)$. We selected the step to be $\Delta m=0.001$ resulting in $\frac{1-0.907}{\Delta m}+1=94$ row. By increasing $\Delta m$, the number of rows can be reduced and interpolation can be used to calculate the angles for a certain $m$ value.

Instead of storing the value of the switching angles $\theta$, it is better to store the duration of the vectors in per unit, which can be calculated as the difference between two consecutive angle values as follows

$$
\tau_{k}=\frac{\theta_{i+1}-\theta_{i}}{2 \pi}, \quad \text { where } j=1 \ldots \frac{\gamma+3}{2}, k=1 \ldots \frac{\gamma+1}{2}
$$

and $\theta_{1}=0$ and $\theta_{\frac{\gamma+3}{2}}=\pi / 6$. For a certain $f_{1}$ fundamental frequency the duration of the vector in $s e c$ can be calculated by multiplying $\tau_{k}$ by the time period $T_{1}$ or dividing it by the frequency $f_{1}$. This way the same array can be used for different $f_{1}$ fundamental frequencies.

For the precise operation, the $\tau_{k}$ lengths of the voltage vectors can be stored as a 16/32 bit signed integer number and fixed point arithmetic can be used during calculation. If the processor has Floating Point Unit (FPU) the value of $\tau_{k}$ can be stored as 32 bit float number. The required memory can be estimated as $M=32 \mathrm{bit} \cdot \mathrm{NrOfRows} \cdot \mathrm{NrOfColumns}=$ 
$32 b i t\left(\frac{0.093}{\Delta m}+1\right)\left(\frac{\gamma+1}{2}\right)$. For example for $\gamma=13$ and $\Delta m=$ 0.001 the required memory is approximately $2.6 \mathrm{kbyte}$, which is generally much smaller than the available flash memory of the up-to-date digital devices.

In the overmodulation region, instead of using the updown counter of the PWM peripheral module, a simple timer (counter) is initialized. Generally the input clock to the timer is derived from the internal clock of the processor, divided by a programmable prescaler. When the timer is enabled, it increments by one on every rising edge of the input clock $T_{\text {tim }}$ and generates an interrupt on a period match, when the counter value equals to the value stored in $P R D$ register. After period match the timer resets. For the better understanding Fig. 9 illustrates the operation of the timer.

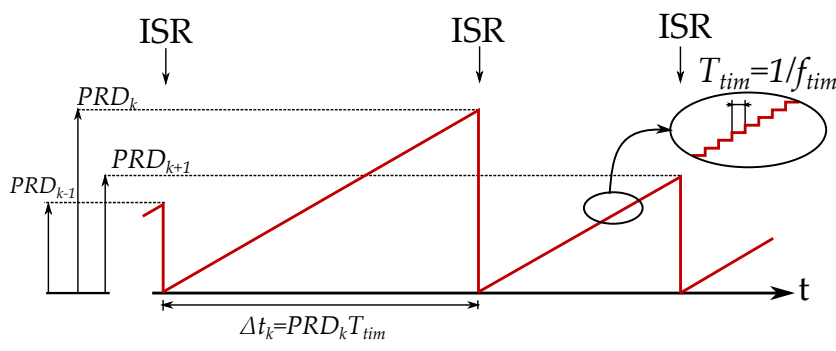

Fig. 9. Operation of the timer applied in the overmodulation region

At every period match an ISR function is called (see Fig. 9). As a first step, the duration of the following voltage vector, which is calculated in the previous step, is loaded to the $P R D$ register. Secondly, the switching signals belonging to the voltage vector are generated by manually overriding/forcing the six output pins of the PWM peripheral. Generally the dead time generator is active during the overriding (some vendor called forcing) option as well.

Finally, the next value of the period register is calculated as

$$
P R D_{k+1}=\tau_{k+1} \frac{T_{1}}{T_{t i m}}=\tau_{k+1} \frac{f_{t i m}}{f_{1}}
$$

where $f_{\text {tim }}=1 / T_{\text {tim }}$ is the frequency of the timer and $\tau_{k+1}$ is read from the previously mentioned two dimensional array.

TABLE I

PARAMETERS OF THE APPLIED DIGITAL DEVICES

\begin{tabular}{l|cc} 
& dsPIC33EP512MU810 & TMS320F28379D \\
\hline CPU frequency & $60 \mathrm{MHz}$ & $200 \mathrm{MHz}$ \\
\hline Flash memory & $512 \mathrm{kbyte}$ & $1 \mathrm{Mbyte}$ \\
\hline Core size & $16 \mathrm{bit}$ & $32 \mathrm{bit}$ \\
\hline FPU & no & yes \\
\hline Used Arithmetic & fixed point & floating point \\
\hline Price (2017) & 9 USD & $35 \mathrm{USD}$
\end{tabular}

\section{EXPERIMENTAL AND SIMULATION RESULTS}

\section{A. Experimental test using two vector and three vector method}

To verify the calculation results just described, laboratory measurements were carried out. Both the two vector and the three vector method were implemented on a 16-bit $\mu C$ (dsPIC33EP512MU810) and on a 32-bit DSP (TMS320F28379D). The experimental results using the $\mu C$ are presented in [31]. In the current paper the results using the DSP are introduced.
During the measurement, a commercially available intelligent three-phase IGBT module from company Fairchild (FSBB30CH60C) was used for the tests. The VSI is supplied from a single phase diode bridge rectifier, therefore the DC link voltage was $2 U_{D C}=320 \mathrm{~V}$. The dead time was selected to be $2 \mu \mathrm{s}$. The torque was measured by an electric torque meter (SILEX TMI-02).

The measurements were carried on an induction machine with rated speed $18 \mathrm{krpm}$. The rated data and main parameters of the machine are: power: $P_{N}=3 \mathrm{~kW}$, rms line-to-line voltage $U_{L L, R M S}=380 \mathrm{~V}$, phase rms current $I_{N, R M S}=7.7 \mathrm{~A}$, rated frequency $f_{1 N}=300 \mathrm{~Hz}$, stator and rotor resistance $R_{S}=1.125 \Omega, R_{R}=0.85 \Omega$, stator and rotor leakage reactance $X_{L S}=4.71 \Omega$ and $X_{L R}=2.63 \Omega$, magnetizing reactance $X_{m}=84.82 \Omega$ (all reactances are at rated frequency) and the number of pole pairs is $p=1$.

The experimental results at no-load are shown in Fig.10. For simplicity, the measurements were carried out at lower fundamental frequencies than the rated one. The motor was started using Space Vector Modulation (SVM) algorithm by keeping the ratio $U_{1} / f_{1}$ constant. The overmodulation region was reached at $f_{1}=180 \mathrm{~Hz}$, where $U_{1}=0.907 U_{1 \max }$. Over $f_{1}=180 \mathrm{~Hz}$ the proposed optimal PWM strategies were applied.

Figure 10(a), 10(b) and 10(c) present the time function and the harmonic spectra of the motor phase voltage, the time function of the motor phase current and the torque pulsation at $f_{1}=180 \mathrm{~Hz}$ and $\gamma=13\left(U_{1}=0.907 U_{1 \max }\right)$ for the $2 \mathrm{~V}$, $3 V-T 1$ and $3 V-T 2$, respectively. The measured WTHD value of the voltage and the THD value of the phase current are also denoted. For a better comparison, the same results were depicted also for SVM on Fig.10(d). The switching frequency for SVM was $13 \cdot 180=2.34 \mathrm{kHz}$ to obtain the same number of switching over one fundamental period. As it can be seen, $3 \mathrm{~V}-\mathrm{T} 1$ and $3 \mathrm{~V}-\mathrm{T} 2$ have better performance over $2 \mathrm{~V}$ method and SVM algorithm. The influence of the higher voltage harmonics is considerably lower. The peak-to-peak value of the torque pulsation is practically half for $3 \mathrm{~V}-\mathrm{Tl}$ by comparing it with $2 \mathrm{~V}$ or with $3 \mathrm{~V}-\mathrm{T} 2$. The results are in line with the calculated one, presented in the previous section (see Fig.8).

By increasing the fundamental frequency and $U_{1}$, the performance of $2 \mathrm{~V}$ becomes better than $3 \mathrm{~V}-\mathrm{Tl}$ or $3 \mathrm{~V}-\mathrm{T} 2$ (see Fig.6(c) and 12(c) later). For example, for $\gamma=13$ it is valid for $m \geq 0.945$

By further increasing the fundamental frequency and $U_{1}$, the duration of the zero voltage vector became zero (for $\gamma=13$ when $m \geq 0.952$ ) consequently $3 \mathrm{~V}-\mathrm{Tl}$ effectively reduces to a two vector method with $\gamma *=\gamma-4$ (Fig.10(f)). Figure 10(e) and $10(\mathrm{f})$ show experimental results for $m=0.96\left(f_{1}=190\right.$ $\mathrm{Hz}$ ). It can be seen that, the harmonic performance of the $2 \mathrm{~V}$ is better than $3 \mathrm{~V}-\mathrm{Tl}$ at $\gamma=13$, as the latter one is effectively a two vector method with $\gamma *=13-4=9$.

Fig. 11 presents the measured trajectories of the stator current space vector $\mathbf{i}_{s}$ for $3 V-T 1$ and $3 V-T 2$ for $\gamma=9,13,21$ and 31 at $m=0.92\left(f_{1}=183 \mathrm{~Hz}\right)$. The THD value of the current signals is also depicted. As it can be seen, the performance of $3 \mathrm{~V}-\mathrm{Tl}$ or $3 \mathrm{~V}-\mathrm{T} 2$ in the lower part of the overmodulation region is acceptable even for low $\gamma$ values. At $m=0.92$ the $I_{T H D}$ value is lower using $3 \mathrm{~V}$-T2 than using $3 \mathrm{~V}$-T1 for $\gamma=9$ 

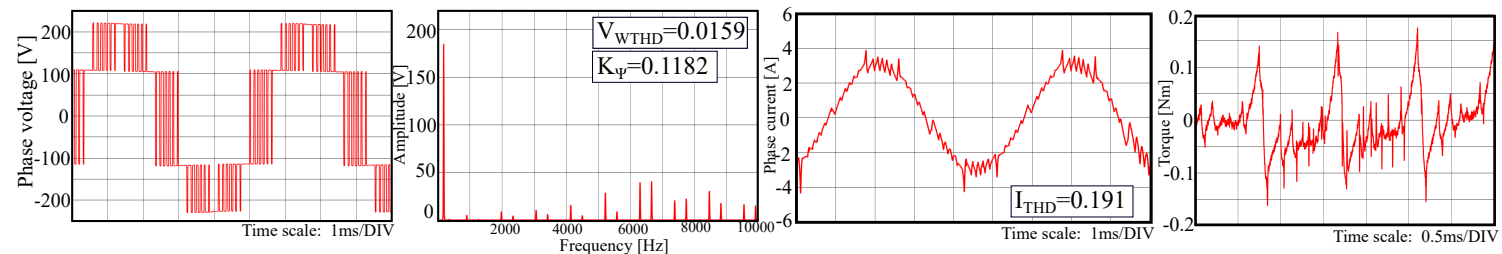

(a) $2 V, \gamma=13, m=0.907, f_{1}=180 \mathrm{~Hz}, f_{c} \approx 2.34 \mathrm{kHz}$
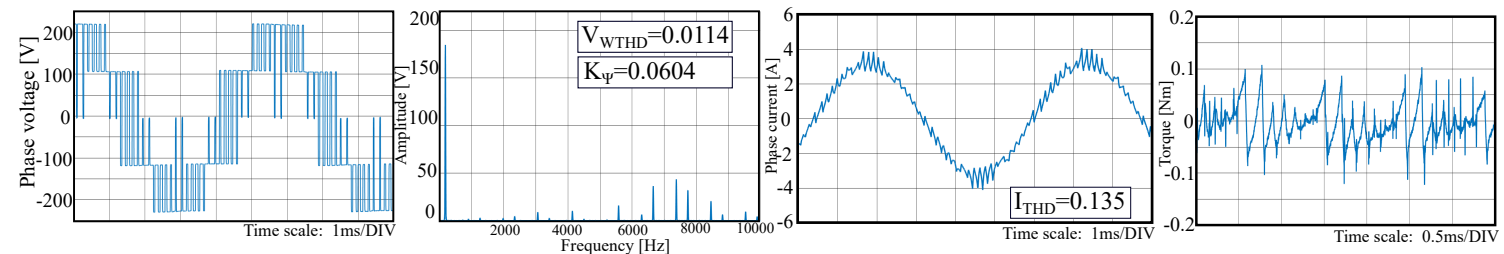

(b) $3 \mathrm{~V}-\mathrm{T} 1, \gamma=13, m=0.9, f_{1}=180 \mathrm{~Hz}, f_{c} \approx 2.34 \mathrm{kHz}$
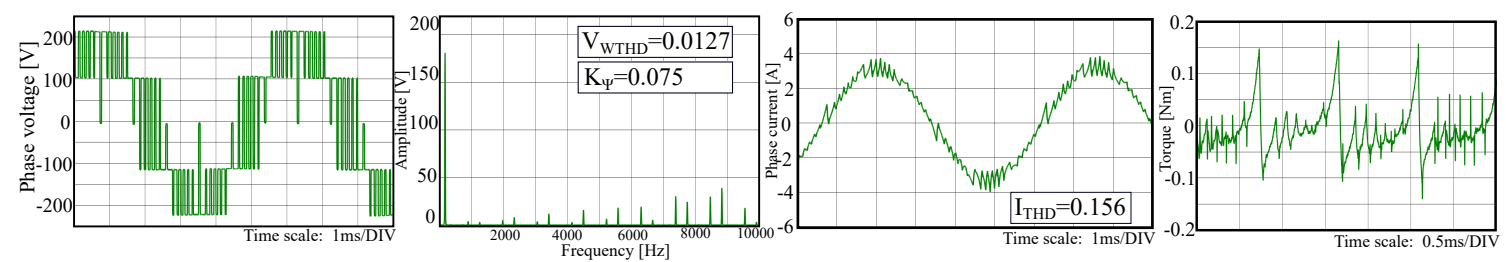

(c) $3 V-T 2, \gamma=13, m=0.9, f_{1}=180 \mathrm{~Hz}, f_{c} \approx 2.34 \mathrm{kHz}$
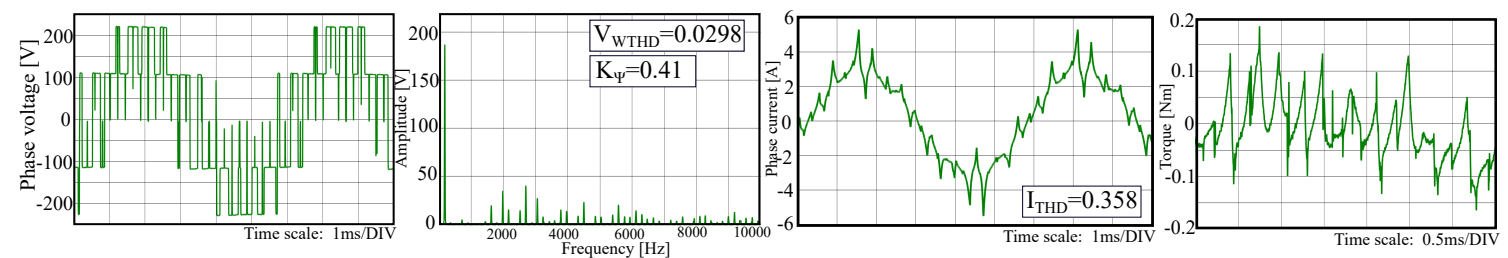

(d) Space Vector Modulation, $f_{c}=2.34 \mathrm{kHz}\left(m_{f}=13\right), m=0.907, f_{1}=180 \mathrm{~Hz}$
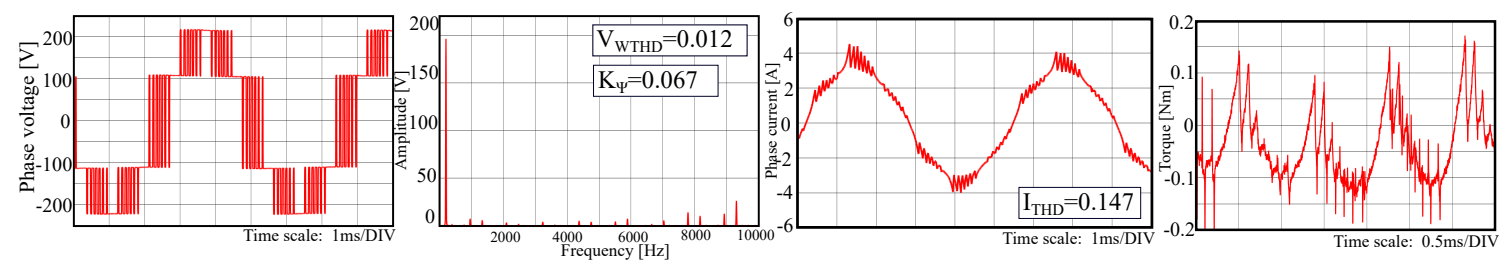

(e) $2 V, \gamma=13, m=0.96, f_{1}=190 \mathrm{~Hz}, f_{c} \approx 2.47 \mathrm{kHz}$
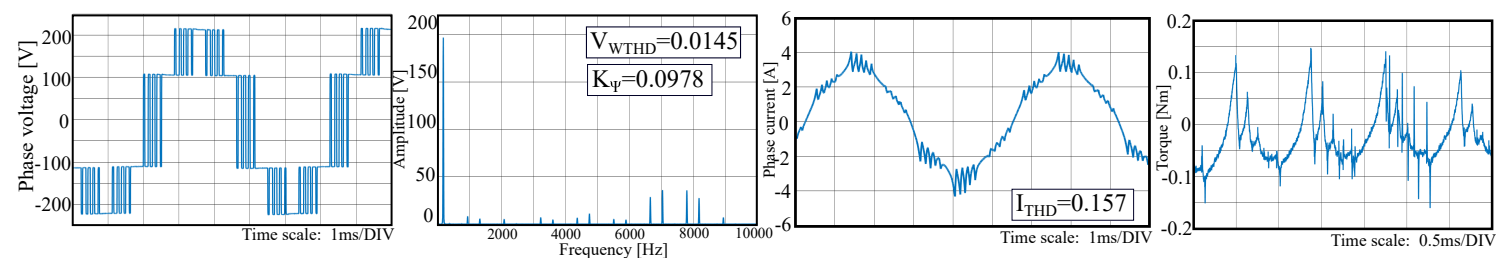

(f) $3 V-T 1, \gamma=13$ (effectively $2 V$ with $\gamma=9$ ), $m=0.96, f_{1}=190, f_{c} \approx 1.7 \mathrm{kHz} \mathrm{Hz}$

Fig. 10. Experimental test results at no-load, time function of phase voltage (left), time function of phase current (middle), time function of torque signal and harmonic spectra of phase voltage (right)

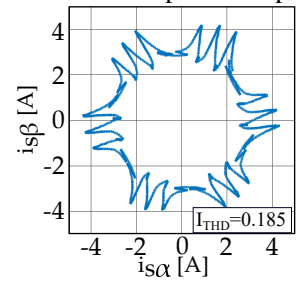

(a) $3 V-T 1, \gamma=9$

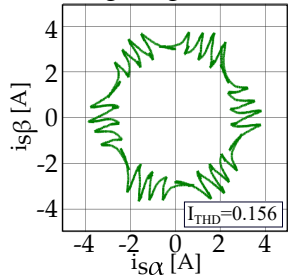

(b) $3 V-T 2, \gamma=9$

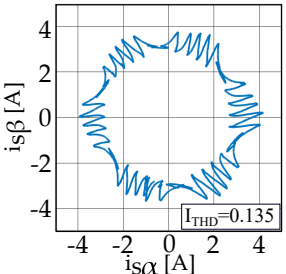

(c) $3 \mathrm{~V}-\mathrm{Tl}, \gamma=13$

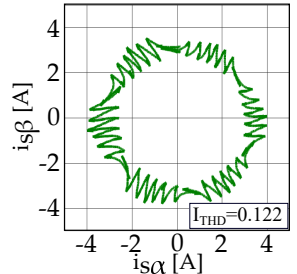

(d) $3 V-T 2, \gamma=13$

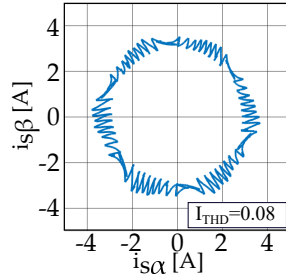

(e) $3 \mathrm{~V}-T 1, \gamma=21$

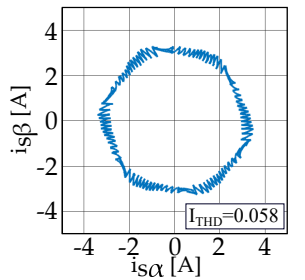

(f) $3 \mathrm{~V}-T 1, \gamma=31$

Fig. 11. Experimental test results at no-load, trajectories of the stator current space vector, three vector methods, $m=0.92, f_{1}=183 \mathrm{~Hz}$ 
and $\gamma=13$. This result is in line with the loss-factor curves presented in Fig.6(b) and 6(c).

\section{B. Comparison with existing overmodulation techniques}

To compare the proposed two optimized PWM techniques with other techniques available in the literature, the $V_{W T H D}$ values are calculated for a few $\gamma$ values $(5,7,9,13,21,31)$. The calculation is done by simulating the motor drive system presented previously using Matlab/Simulink and using the FFT() function to determine the harmonics. To validate the simulation results, the values are checked in some working point $(m=0.9,0.92,0.94,0.96)$ by experiments as well. The curves can be seen on Fig.12.

In papers [5] and [6] the overmodulation region of four PWM techniques, like conventional space vector strategy (CSVS), basic bus clamping strategy (BBCS), boundary sampling strategy (BSS) and asymmetric zero-changing strategy (AZCS) are studied for different pulse ratios $(P=\gamma)$ and different clamping angles. By comparing the $V_{W T H D}$ curves presented in this paper with the curves shown on Fig.15 in [5] and Fig.14 in [6] at the same pulse ratio, it can be concluded that the presented optimized PWM techniques have better harmonic performance. For example, the lowest $V_{W T H D}$ value $\left(V_{W T H D}=0.0125\right)$ in [5] occurs applying BSS with $30^{\circ}$ clamping angle at $\gamma=21$ around $m=0.9$ (Fig.15c in [5]). Using the $3 V-T 1$ and $\gamma=21$ the $V_{W T H D}=0.0125$ value is reached only in the upper part of the overmodulation range $\left(m=0.965\right.$, see Fig12(c)) and the lowest $V_{W T H D}$ value is 0.00465 .

By applying 2-zone AZCS with with $60^{\circ}$ or $30^{\circ}$ clamping angle at $\gamma=13$, the $V_{W T H D}$ is practically constant and equals to 0.02 in the lower part of overmodulation region $(m \leq 0.96)$ as it was presented in Fig.14c and 14f in [6]. As it can be seen on Fig.12(b)) by using $3 V-T 1$ or $3 V-T 2$ the $V_{W T H D}$ is considerably lower (around 0.012).

An optimized PWM technique for the whole modulation range is studied in [22] for $\gamma=5,7,9$ and 11, where the optimization is done to minimize $V_{W T H D}$, which is the square root of the loss-factor (see (3)). By comparing the $V_{W T H D}$ curves presented in this paper with the curves shown on Fig.13 in [22] at the same pulse ratio, it can be concluded the results are very similar using $3 \mathrm{~V}-\mathrm{Tl}$ or $3 \mathrm{~V}-\mathrm{T} 2$ in the lower part and $2 \mathrm{~V}$ method in the upper part of overmodulation region for $\gamma=5,7$ and 9 . The lowest $V_{W T H D}$ value for $\gamma=5$ and $\gamma=7$ occur around $m=0.96$ is 0.02 and 0.015 in [22], respectively. Very similar values can be read from 12(a). For $\gamma=9$ the lowest $V_{W T H D}$ value is around 0.01 in [22]. In our case the minimum $V_{W T H D}$ is slightly higher: for $\gamma=9$ the lowest $V_{W T H D}$ value is 0.012 .

\section{CONCLUSIONS}

Three harmonic loss-optimized PWM control methods in overmodulation region of three phase inverter-fed ac drives are investigated. It is shown that, the two vector method $(2 \mathrm{~V})$, which does not utilize the zero voltage vectors is able to produce an optimized control with an acceptable quality only in the upper part of overmodulation region. By using zero voltage vector (Three vector method type $1(3 \mathrm{~V}-T 1)$ or type 2 $(3 V-T 2))$ in the lower part $\left(m=U_{1} / U_{1 \max } \leq 0.9514\right)$ of the overmodulation region, a considerably better performance can be obtained.

It is presented $3 V-T 1$, where the voltage vector sequence starts with $\mathbf{U}=\left[\mathbf{U}_{I}, 0, \mathbf{U}_{I}, \mathbf{U}_{I I} \ldots\right]$, has considerably better performance at the beginning of overmodulation region than $3 \mathrm{~V}-\mathrm{T2}$, where the voltage vector sequence is $\mathbf{U}=$ $\left[0, \mathbf{U}_{I}, \mathbf{U}_{I I}, \ldots\right]$ when $\gamma>11$. In the middle of the overmodulation region the performance of $3 \mathrm{~V}-\mathrm{T} 2$ becomes better.

The optimized control for the three methods is computed for number of inverter switching $\gamma=5,7,9,11,13,15,21,31$ and 43 on $1 / 6$ th of fundamental period. Investigation of the drive with these switching numbers has shown:

a) Motor harmonic losses in the range of $0.98 \leq m \leq 1$ are virtually independent on the number of inverter switching. When $0.9 \leq m \leq 0.96$ and the number of switching is $\gamma \geq 13$ the motor harmonic losses will be so small that the influence of these losses on the motor heating can be neglected. It is also true for $0.9 \leq m \leq 0.975$ if $\gamma$ is increased to 31 .

b) Motor torque pulsation and especially the torque of $6^{\text {th }}$ order in case of $0.95 \leq m \leq 1$ can not be sensibly decreased by increasing the switching number $\gamma$. Furthermore, for $0.9 \leq$ $m \leq 0.93$ the torque of $6^{t h}$ order becomes almost zero and the torque pulsation of high frequency becomes dominant when $\gamma \geq 9$. As it was shown, the torque pulsation of $3 \mathrm{~V}-\mathrm{Tl}$ is lower than the torque pulsation of $3 V-T 2$ at the same $\gamma$.

The results of computations were verified by simulation and experimental tests on a high speed induction machine. The simulated and measured $V_{W T H D}$ curves are compared with the results obtained by other existing overmodulation strategies like conventional space vector strategy (CSVS), basic bus clamping strategy (BBCS), boundary sampling strategy (BSS) and asymmetric zero-changing strategy (AZCS). It can be concluded that, the optimized technique has considerably better harmonic performance at the same pulse ratio.

In summary, it can be concluded that, an acceptable drive condition can be obtained, even for low $\gamma$, by applying one of the three vector methods $(3 \mathrm{~V}-T 1$ or $3 \mathrm{~V}-\mathrm{T} 2)$ in the lower part and the two vector method in the upper part of modulation region. It makes the techniques applicable to operate high speed, high pole-count drives or high power drive systems in the overmodulation region.

\section{ACKNOWLEDGEMENT}

This paper was supported by the János Bolyai Research Scholarship of the Hungarian Academy of Sciences. Supported by the UNKP-17-4-I New National Excellence Program of the Ministry of Human Capacities. Research supported by the National Research, Development and Innovation Office (NKFIH) under the grant FK 124913.

\section{REFERENCES}

[1] D. G. Holmes and T. A. Lipo, Pulse width modulation for power converters: principles and practice. John Wiley \& Sons, 2003, vol. 18

[2] A. Tenconi, S. Vaschetto, and A. Vigliani, "Electrical machines for high-speed applications: Design considerations and tradeoffs," IEEE Transactions on Industrial Electronics, vol. 61, no. 6, pp. 3022-3029, June 2014

[3] J. Holtz, W. Lotzkat, and A. M. Khambadkone, "On continuous control of pwm inverters in the overmodulation range including the six-step mode," IEEE Transactions on Power Electronics, vol. 8, no. 4, pp. 546553, Oct 1993 


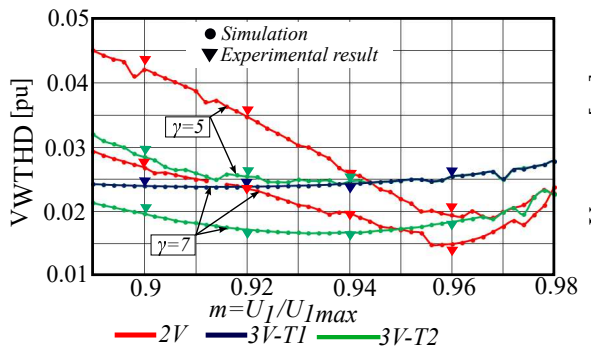

(a) $\gamma=5,7$

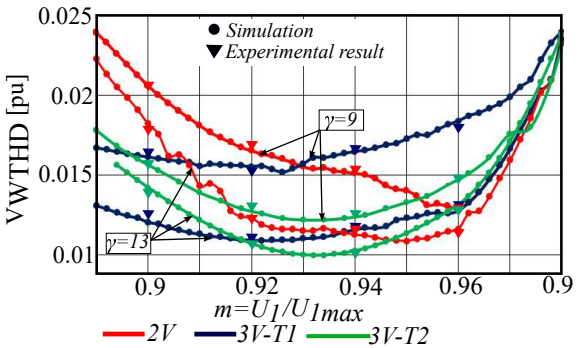

(b) $\gamma=9,13$

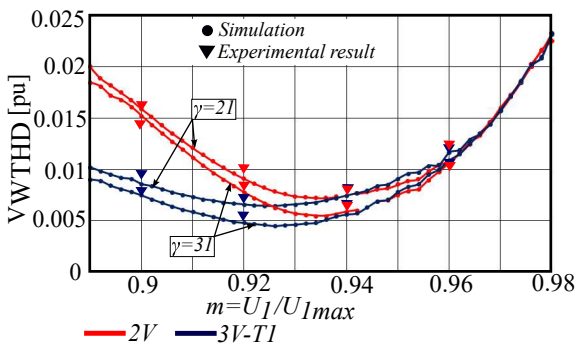

(c) $\gamma=21,31$

Fig. 12. $V_{W T H D}$ curves versus $m$ obtained by simulation and experimental test

[4] M. K. Modi, S. Venogupal, and G. Narayanan, "Space vector-based analysis of overmodulation in triangle-comparison based pwm for voltage source inverter," Sadhana, vol. 38, no. 3, pp. 331-358, Jun 2013.

[5] G. Narayanan and V. T. Ranganathan, "Overmodulation algorithm for space vector modulated inverters and its application to low switching frequency pwm techniques," IEE Proceedings - Electric Power Applications, vol. 148 , no. 6 , pp. 521-536, Nov 2001.

[6] - "Extension of operation of space vector pwm strategies with low switching frequencies using different overmodulation algorithms," IEEE Transactions on Power Electronics, vol. 17, no. 5, pp. 788-798, Sep 2002.

[7] M. K. Modi, S. Venugopal, and G. Narayanan, "Analysis and comparison of overmodulation algorithms for space vector modulated voltage source inverter," EPE Journal, vol. 24, no. 4, pp. 38-47, 2014.

[8] S. Bolognani and M. Zigliotto, "Novel digital continuous control of svm inverters in the overmodulation range," IEEE Transactions on Industry Applications, vol. 33, no. 2, pp. 525-530, Mar 1997.

[9] M. K. Modi and G. Narayanan, "Improved single-zone overmodulation algorithm for space vector modulated inverters," in Power Electronics, Drives and Energy Systems (PEDES), 2014 IEEE International Conference on, Dec 2014, pp. 1-6.

[10] G. Narayanan, "Synchronised pulsewidth modulation strategies based on space vector approach for induction motor drives," Ph.D. dissertation, Indian Inst. Sci., Bangalore, India, 1999.

[11] J. Holtz, "Advanced pwm and predictive control - an overview," IEEE Trans. on Industrial Electronics, vol. 63, no. 6, pp. 3837-3844, June 2016.

[12] J. Prieto, F. Barrero, M. J. Durn, S. T. Marn, and M. A. Perales, "Svm procedure for $n$-phase vsi with low harmonic distortion in the overmodulation region," IEEE Trans. on Industrial Electronics, vol. 61, no. 1, pp. 92-97, Jan 2014.

[13] K. Kondo and S. Doki, "Improvement of transient state characteristic for vector control system by using the inverter overmodulation range," in Power Electronics and Applications (EPE'15 ECCE-Europe), 2015 17th European Conference on, Sept 2015, pp. 1-7.

[14] S. K. Sahoo and T. Bhattacharya, "Rotor flux-oriented control of induction motor with synchronized sinusoidal pwm for traction application," IEEE Trans. on Power Electronics, vol. 31, no. 6, pp. 4429-4439, June 2016.

[15] Y. Park, S. K. Sul, and K. N. Hong, "Linear over-modulation strategy for current control in photovoltaic inverter," in 2014 International Power Electronics Conference (IPEC-Hiroshima 2014 - ECCE ASIA), May 2014, pp. 2598-2605.

[16] G. S. Buja and G. B. Indri, "Optimal pulsewidth modulation for feeding ac motors," IEEE Trans. on Industry Applications, vol. IA-13, no. 1, pp. 38-44, Jan 1977.

[17] S. Halasz, "Optimal control of voltage source inverters supplying asynchronous motors," in Proceedings of International Conference on Electrical Machines ICEM, Brussels, 1978, pp. 3-5.

[18] — , "Optimized control of pwm inverters for a given number of commutations (in hungarian)," Elektrotechnika, vol. 76, no. 10-11, pp. 386-391, March 1983.

[19] M. Bierhoff, H. Brandenburg, and F. W. Fuchs, "An analysis on switching loss optimized pwm strategies for three phase pwm voltage source converters," in Industrial Electronics Society, 2007. IECON 2007. 33rd Annual Conference of the IEEE, Nov 2007, pp. 1512-1517.

[20] J. Holtz and X. Qi, "Optimal control of medium-voltage drives - an overview," IEEE Transactions on Industrial Electronics, vol. 60, no. 12, pp. 5472-5481, Dec 2013.

[21] Q. Lei, D. Cao, and F. Z. Peng, "Novel loss and harmonic minimized vector modulation for a current-fed quasi-z-source inverter in hev motor drive application," IEEE Trans. on Power Electronics, vol. 29, no. 3, pp. 1344-1357, March 2014
[22] A. Tripathi and G. Narayanan, "Investigations on optimal pulse width modulation to minimize total harmonic distortion in the line current," IEEE Transactions on Industry Applications, vol. 53, no. 1, pp. 212-221, Jan 2017.

[23] V. S. S. P. K. Hari and G. Narayanan, "Theoretical and experimental evaluation of pulsating torque produced by induction motor drives controlled with advanced bus-clamping pulsewidth modulation," IEEE Transactions on Industrial Electronics, vol. 63, no. 3, pp. 1404-1413, March 2016.

[24] A. Khamitov and A. Ruderman, "Synchronous optimal modulation: Frequency or time domain, global or constrained optimization? 40 years to the first formulation," IEEE Transactions on Industrial Electronics, vol. 64, no. 11, pp. 8778-8781, Nov 2017.

[25] A. Edpuganti and A. K. Rathore, "Optimal pulsewidth modulation of medium-voltage modular multilevel converter," IEEE Transactions on Industry Applications, vol. 52, no. 4, pp. 3435-3442, July 2016.

[26] D. O. Neacsu, Y. Zheng, and B. Lehman, "An sd card flash-memorybased implementation of a multioptimal three-phase pwm generator," IEEE Transactions on Power Electronics, vol. 31, no. 1, pp. 39-51, Jan 2016.

[27] S. Halasz, I. Varjasi, and A. Zacharov, "Overmodulation strategies of inverter-fed ac drives," in Power Conversion Conference, 2002. PCCOsaka 2002. Proceedings of the, vol. 3, 2002, pp. 1346-1351 vol.3.

[28] A. Tripathi and G. Narayanan, "Evaluation and minimization of loworder harmonic torque in low-switching-frequency inverter-fed induction motor drives," IEEE Transactions on Industry Applications, vol. 52, no. 2, pp. 1477-1488, March 2016.

[29] K. Basu, J. S. S. Prasad, G. Narayanan, H. K. Krishnamurthy, and $\mathrm{R}$. Ayyanar, "Reduction of torque ripple in induction motor drives using an advanced hybrid pwm technique," IEEE Transactions on Industrial Electronics, vol. 57, no. 6, pp. 2085-2091, June 2010.

[30] G. Gohil, R. Maheshwari, L. Bede, T. Kerekes, R. Teodorescu, M. Liserre, and F. Blaabjerg, "Modified discontinuous pwm for size reduction of the circulating current filter in parallel interleaved converters," IEEE Transactions on Power Electronics, vol. 30, no. 7, pp. 3457-3470, July 2015.

[31] P. Stumpf and S. Halasz, "Optimization of pwm for overmodulation region of two-level inverters," in 2016 IEEE International Power Electronics and Motion Control Conference (PEMC), Sept 2016, pp. 174179. 